\title{
THE ETIOLOGY OF PHOBIAS: A NONASSOCIATIVE ACCOUNT
}

\author{
Ross G. Menzies \\ Department of Behavioural Sciences, Faculty of Health Sciences, \\ The University of Sydney \\ J. Christopher Clarke
}

School of Psychology, The University of New South Wales

\begin{abstract}
Theories of the origin and maintenance of fears and phobias have had a profound influence on the kinds of treatments employed in the phobic disorders. In view of this influence, the present review considers the considerable controversy surrounding the major etiological models. First, the various forms of the associative learning account are examined. It is argued that each of these approaches has failed to provide a comprehensive account of the onset of the phobic disorders. Second, evidence for a nonassociative account is considered. It is argued that this latter model can more adequately account for the majority of experimental and clinical findings in most phobic conditions. Future directions for research on the etiology of phobias are discussed.
\end{abstract}

INCREASINGLY, clinicians and researchers alike are recognising the need to collect information about the origins of phobic cases as a standard part of initial assessment. This information enables the researcher to evaluate the relevance of the various theoretical approaches, and may provide useful data for the clinician who must choose an appropriate treatment strategy. It has been argued that different modes of onset may lead to different individual response patterns and result in differential response to standard treatments (Rachman, 1977). Thus, theories of the origin and maintenance of fears and phobias continue to have a profound influence on the kinds of treatments employed with phobic patients. It is largely in view of this influence that the present paper focuses on the major etiological accounts, beginning with a review of the traditional conditioning model and the psychoanalytic account that it sought to replace.

Correspondence should be addressed to Ross G. Menzies, Department of Behavioural Sciences, Faculty of Health Sciences, The University of Sydney, P.O. Box 170, Lidcombe, New South Wales, 2141, Australia. 


\section{THE CLASSICAL CONDITIONING ACCOUNT}

Though proposed as early as 1917 , the Pavlovian model of phobic reactions was not to become the dominant etiological account until well after the Second World War. It was not until publication of Wolpe and Rachman's (1960) classic critique of Freud's famous case study, "Little Hans," that the conditioning account was to take centre stage. As many have subsequently argued, the Wolpe and Rachman (1960) paper represents as clearheaded a critique of the looseness of analytic inference and argument as exists in the literature (Seligman, 1971). Its influence on the growth of interest and acceptance of the conditioning model, and the demise of the analytic account, cannot be overestimated.

Freud had argued that Hans' fear of horses, like all phobias, was due to repressed sexual wishes. According to Freud (1909), due to naturally occurring Oedipal strivings for his mother, Hans wished to replace his father, whom he hated as a rival, and then sleep with his mother. Freud (1909) states that, "Hans really was a little Oedipus who wanted to have his father 'out of the way', to get rid of him, so that he might be alone with his beautiful mother and sleep with her" (p. 269). His Oedipal desires and his rivalrous aggression toward his father were repressed as unacceptable forces to his ego. The anxiety related to his father, involving a fear of retribution in the form of castration, was alleviated by its displacement onto horses, animals which had become associatively linked with his conflict and therefore symbolic of his father. Hans' fear of walking on the streets, where horses were to be found, provided a means for him to stay at home with his mother. Finally, instead of killing his father, Hans resolved his Oedipal conflict by promoting his father to a marriage with his grandmother in a game, thus removing the rival.

That a plausible learning-based alternative to the psychoanalytic view of Hans' fear existed was made more than clear by Wolpe and Rachman (1960) in their classic rejoinder. They reported that in the 140-page description of the case, they could find no direct evidence of Hans' wish to sleep with his mother, nor of his hatred or fear of his father. Indeed, Hans had expressly denied both these emotions. Similarly, they found no satisfactory evidence for the supposed relationship between horses and Hans' father. Evidence for this relationship had been based on Hans' fear of "what horses wear in front of their eyes and the black around their mouths" (Freud, 1909, p. 211), which had been interpreted by Freud as the transposed eyeglasses and moustache of his father. However, Wolpe and Rachman point out that such an interpretation is seriously undermined by Hans' later revelation that he had meant blinkers and muzzles, respectively. Finally, they argued that Freud's claim that the purpose of Hans' "agoraphobic" behaviour was simply to keep him near his mother failed to account for the fact that Hans also experienced anxiety when he was out walking with his mother.

With their attack on the Freudian account complete, Wolpe and Rachman (1960) went on to provide an alternative account of Hans' phobic behaviour. They noticed that prior to onset of Hans' concerns, he had suffered a traumatic experience involving horses. Hans had been startled by an accident in which a horse pulling a bus had fallen. By his own account, the event had caused him great distress. Furthermore, as confirmed by his mother, his fear of horses had broken out immediately afterwards. Unlike Freud, Wolpe and Rachman saw the complete cause of Hans' disorder in this event, arguing that his phobic concerns, and all phobias, were due to traumatic Pavlovian conditioning. In the basic Pavlovian case, a neutral stimulus (the conditioned stimulus or CS) may acquire the capacity to elicit fear (the conditioned response or $\mathrm{CR}$ ) if it occurs in contiguity with a second stimulus (the unconditioned 
stimulus or UCS) that inherently elicits fear or pain (unconditioned response or UCR). Hence, in Hans' case, horses (CS) had supposedly acquired the capacity to elicit fear (CR) after being involved in the accident (UCS) that had caused the initial startle and distress (UCR).

As already stated, Wolpe and Rachman (1960) were not the first to endorse a Pavlovian account of the acquisition of phobias. Watson and Morgan (1917) had argued much earlier that respondent conditioning could result in fear acquisition. This had been claimed to be demonstrated by Watson and Rayner (1920), in the famous case of the 11-month old infant named Albert. The boy was rendered fearful of white furry objects after a brief series of trials consisting of temporally contiguous pairings of a white laboratory rat (CS) and a loud aversive noise (UCS). Prior to the pairings, Albert had displayed no fear in the presence of the rat. However, after only a few CS-UCS trials, Albert began to show distress and withdraw whenever the rat was presented alone. In a demonstration of stimulus generalization, Albert subsequently showed distress to objects resembling the CS, including fur coats and a mask of Santa Claus with a long white beard.

The case of Little Albert has been regarded by many as the exemplar of phobia genesis through Pavlovian conditioning. It is therefore interesting, as Delprato and McGlynn (1984) note, that an instrumental contingency existed between Albert's behaviour and the presentation of the loud noise. That is, the noise was presented only when Albert reached out and touched the rat. Despite this, Watson and Rayner (1920) saw no role for Thorndike's (1898) instrumental paradigm in emotional behaviour. Like other early behaviourists, Watson erred by equating all learning with Pavlovian conditioning. It was not until Mowrer's (1939) extension of Watson's account that instrumental learning was seen to take an important role in the development and maintenance of phobias.

Mowrer (1939) saw fear as more than simply a reaction to a CS. He argued that fear could serve as an acquired source of motivation or drive, exciting behaviour just as the primary drives could. Furthermore, he claimed that behaviours which reduced fear would be reinforced. That is, their probability of recurrence would increase. Hence, the model attempted to account for development of avoidance behaviour, which was said to be motivated by fear and reinforced by fear reduction. In the present context however, the most important point to note is that, like the Watsonian account, and all conditioning accounts since, Mowrer (1939) claimed that the initial acquisition of fear was due to Pavlovian conditioning.

The traditional Pavlovian account of fear acquisition has enjoyed widespread acceptance with a variety of laboratory and clinical data cited in its support. Various physiological and motoric responses indicative of fear have been classically conditioned in both animals and humans in the laboratory. In addition, some phobic patients have been able to recall traumatic conditioning episodes at the beginning of their phobic concerns (e.g., Liddell \& Lyons, 1978; Merckelbach, De Ruiter, Van De Hout, \& Hoekstra, 1989). Despite such support however, a number of criticisms of the model have been offered, casting doubt on its adequacy as a comprehensive account of the genesis of phobias. Some of the common objections, as proponents of the conditioning account point out, prove lame on close inspection. Others, however, are quite compelling. In order to give a balanced view, the dubious attacks will be examined before reviewing the more potent criticisms.

Perhaps the weakest of the common attacks on the conditioning account focuses on the infrequency of one-trial learning in the laboratory. It has been argued that implicit in the general-process learning view of phobias is the assumption that only 
one conditioning trial is often necessary for acquisition (Seligman, 1971). This assumption appears necessary to account for the acute onset of many phobic reactions. Contrary to the assumption, it has been commonly claimed that one-trial conditioning is extremely rare in the laboratory (Eysenck. 1979; Seligman, 1971; Sturgis \& Scott, 1984). Seligman (1971) claims that laboratory fear conditioning typically takes between three and six trials. He argues that conditioning in one trial is usually only obtained if extremely traumatic UCSs are used.

However, even some committed opponents of the traditional conditioning account have recognised the inadequacy of this attack. Gray (1979) argues that onetrial conditioning, far from being rare in the laboratory, is actually employed as a procedural strategy in some research. Levis (1979) agrees, pointing out further that if safe and noxious situations are made highly discriminable, learning in animals may be very rapid. Summarizing much of his research, he reports that in order to reach a criterion of 10 consecutive avoidances in a one-way situation, the mean number of shock trials required was two or three, with many subjects learning after one (e.g., Levis, 1970, 1971; Levis, Bouska, Eron, \& McIlhon, 1970). In addition, it has been noted that attempts to demonstrate differential rates of conditioning of autonomic responses to various CSs in human subjects have been plagued by the speed of acquisition of conditioned responses (Hodes, 1981; Marks, 1987). Full-blown conditioning of skin conductance in a single trial using relatively mild electric shock paired with a variety of CSs is commonplace (Marks, 1987). In sum, single-trial conditioning of fear has been commonly observed in both animals and humans, and not only with supertraumatic UCSs.

An even more common, but equally unconvincing attack on the conditioning case centres on several reported failures to demonstrate fear conditioning in children in the years following Watson and Rayner's (1920) original demonstration with Albert. Many authors have suggested that the reports of Bregman (1934), English (1929), and Valentine (1930) question the comprehensiveness of the traditional Pavlovian account (e.g., Costello, 1970; Eysenck, 1976, 1979; Gray, 1971; Marks, 1969, 1987; Rachman, 1977; Seligman, 1970, 1971; Thorndike, 1935). English (1929) reported on several attempts to condition fear. Whereas conditioning was obtained to a black stuffed cat, no evidence of conditioned fear was found in a second case, despite more than 50 trials, when a childs toy was used as the CS. Bregman (1934) claimed similar difficulty in conditioning fear when household objects were used as CSs with 15 children aged from 8 to 16 months. Following conditioning trials, subjects reportedly displayed no more fear to the household objects paired with the aversive UCS (a loud bell) than they did to other stimuli paired with a positive UCS (a rattle or pleasant melody). Valentine (1930) reports on uncontrolled observations of his own children. Whereas he was able to condition fear to a caterpillar after contiguous pairings with the sound of a loud whistle, similar pairings did not result in conditioning when the CS was a pair of opera glasses.

Levis (1979) and Delprato (1980), however, have cogently argued that failures to acquire fear in these studies may reflect methodological inadequacies rather than the inappropriateness of a Pavlovian model of fear. They point out that English's (1929) failure to condition fear to a child's toy seems due to the lack of a functional UCS. English clearly reports that his UCS (the noise) "failed to evoke fear" (p. 222) at any time. Without an effective UCS, no conditioning would be expected. Although UCS effectiveness was established by Bregman (1934), she failed to determine whether the CSs used were discriminable by the young infants. Furthermore, even if they were discriminable, it is doubtful that sufficient differential training could have occurred due 
to Bregman's mixture of acquisition and extinction trials and use of too few CS-UCS pairings (Levis, 1979). In regard to Valentine's (1930) observations, only two CS-UCS pairings were given with the opera glasses compared to four pairings with the caterpillar. Secondly, the whistle appears to have been minimally effective as a UCS. Not surprisingly then, close examination of the report questions whether any conditioning took place to either CS (see further, Delprato, 1980).

Other failures to acquire fear have been cited as a significant problem for the conditioning account. Rachman (1977) and others have argued that the failure of individuals who experienced war-time air-raids to develop phobias represents a serious difficulty for the conditioning account. However, as Rachman (1977) admits, fear induction did occur in at least some individuals enduring such raids. Secondly, the failure of many to acquire lasting fears may be understood from a contingency rather than a contiguity view of Pavlovian conditioning. It is now widely argued that Pavlovian conditioning depends on the correlation between the CS and the UCS, rather than on simple contiguity (Rescorla, 1972). Random pairing of a neutral stimulus with an exploding missile may not lead to conditioning, since a CS may need to become highly predictive of the UCS. Thus, through constant CS-UCS pairings one may expect, for example, bomb shelters to provoke anxiety, but not other stimuli that were infrequently and randomly paired with attack. Furthermore, the phenomenon of latent inhibition may account for the failure of many stimuli associated with airraids to become fear provoking. Nonreinforced preexposure to a CS can significantly retard subsequent conditioning to that stimulus (Mackintosh, 1974). Thus, stimuli that had been encountered daily for many prewar years in nonaversive ways prior to being paired with an aversive wartime UCS would be resistant to conditioning. In sum, fear reactions may have predominantly become attached to certain stimuli predictive of attacks and ordinarily not encountered in everyday pre- and postwar life (e.g., bomb shelters), perhaps negating the need for treatment. While this is clearly speculation, and the lack of increase in phobic disorders may be surprising, it is not clear that uncontrolled war-time observations can pose the problem for the conditioning account that some have claimed.

Rachman (1977) describes more controlled observations of failures to acquire fear that again fall short as crippling criticisms of the conditioning account. Summarizing electrical aversion therapy research he points out that it is rare for subjects to develop phobias of the CSs paired with shock despite frequent controlled pairings (Hallam \& Rachman, 1976; Hallam, Rachman, \& Falkowski, 1972). Similar observations have been made by Marks (1987) in regard to sexual fetishism. It is very difficult to produce phobias of fetish objects by pairing them with electric shocks (Bancroft \& Marks, 1968). However, it must be remembered that such studies use relatively mild levels of shock, with the intensity often set by the subject. Any fear to the CS is limited by the intensity of the UCS and the resultant UCR. Put simply, the CR should not become larger than the UCR. Conditioning theory would not predict the development of intense phobic reactions to a stimulus paired with a mildly aversive UCS. When supertraumatic UCSs have been used, intense phobic reactions to associated stimuli have been induced (e.g., Campbell, Sanderson, \& Laverty, 1964). Furthermore, both the cases of fetish and alcohol treatment involve the pairing of nonneutral stimuli with an aversive UCS. It is assumed that both alcohol- and fetish-related stimuli are appetitive, and thus pairings in therapy with electric shock are more relevant to the deconditioning literature than to the classical conditioning of fear. Such cases do not counter the observation that neutral stimuli can easily become fear provoking with aversive UCSs. It must be remembered, in response to the several cases of failure to acquire 
fear cited, that fear conditioning in animals and humans has frequently been demonstrated in the laboratory to a variety of CSs.

Clearly, then, many of the common attacks on the conditioning model prove inadequate on close examination. Others, however, are somewhat more potent. One major objection to the conditioning account centres on the apparently inextinguishable nature of phobic reactions. It has been pointed out that phobias do not extinguish under conventional procedures which reliably extinguish classically conditioned fear in the laboratory (e.g., Seligman, 1971). Each time an individual encounters the phobic stimuli (CS) in the absence of the original evoking trauma (UCS), he or she is exposed to an extinction procedure and his or her fear (CR) should diminish. In the laboratory, a CS typically becomes impotent within the first few extinction trials (Kimble, 1961), in terms of both behavioural indexes (e.g., Wagner, Siegal, \& Fern, 1967) and physiological indexes (e.g., Black, Carlson, \& Soloman, 1962). Indeed, Watson and Rayner (1920) report that Little Albert's conditioned fear began to wane within several trials and required booster CS-UCS pairings to reinstate it. If the case of Albert is to be the examplar of the conditioning account, how can it be reconciled with the commonly seen persistence of phobic reactions over many years?

On the surface, it may appear that Mowrer's two-stage theory can explain the persistence of phobic behaviour. Certainly, if the phobic stimulus is never encountered, due the development of avoidance behaviour, the conditioned fear will be protected from extinction. This explanation of phobic persistence is still popular today. For example, McNally (1987) has recently stated that "phobias persist because phobics avoid potentially therapeutic exposure to their feared stimuli, not because responses to these stimuli are resistant to extinction. Individuals remain phobic because of a failure of exposure, not a failure of extinction" (p. 298). While this explanation may explain the persistence of some phobic cases, it simply cannot account for the majority. As Clarke and Wardman (1985) point out, most phobics cannot regulate their lives so as to ensure complete avoidance of the phobic stimulus. Indeed, it is often the great frequency with which an individual is encountering the phobic stimulus that leads to the decision to seek treatment (American Psychiatric Association, 1980; Marks, 1987). Of course, avoidance need not be overtly motoric. Avoidance in the form of distraction may serve to reduce stimulus salience, thus protecting fear from extinction. However, many sufferers choose not to avoid or escape the phobic stimulus, preferring to confront their phobic concerns. Many phobics seeking treatment will have faced the phobic stimulus, without covert avoidance or a subsequent aversive UCS, on many occasions (Clarke \& Jackson, 1983). According to Mowrer (1939), such trials should lead to fear reduction and, since fear is motivating flight, avoidance should also diminish. Unfortunately, as evidenced by their call for help, for many phobics this simply does not occur.

The inability of Mowrer's (1939) original account to explain persistent phobic fear and avoidance has led to development of alternative conditioning explanations. Some, like the partial irreversibility of fear account (Solomon \& Wynne, 1954), involve subtle tailoring of Mowrer's theory and seem simply post hoc descriptions of the data rather than explanations of it (Rachman, 1976). Others, like the incubation account (Eysenck, 1979), have proved popular but lack any real experimental support (see further, Bersh, 1980; Kimmel, 1979; McAllister \& McAllister, 1979; Nicholaichuk, Quesnel, \& Tait, 1982). Some, like the serial CS hypothesis (Stampfl, 1991) lack support in clinical samples, whereas others, like the safety-signal account (Rachman, 1983, 1984), seem applicable to only certain phobic disorders (Mattick, 1987; Rachman, 1984). Finally, more promising neo-conditioning explanations, like the 
UCS revaluation account (Davey, 1992), require more experimental support in human studies before they can be regarded as providing a comprehensive account of the apparently inextinguishable nature of some phobic reactions. At this point, then, as evidenced by the lack of consensus among the conditioning proponents, persistence of phobic reactions continues to represent a difficulty for the general-process conditioning account.

A related objection to the Pavlovian conditioning model centres on the noncognitive or irrational nature of phobic reactions. It has been noted that experimentally induced autonomic fear responses can be readily eliminated by simply informing the subject that the UCS will no longer follow the CS (Grings, 1973). In contrast, simply telling the phobic sufferer that an aversive UCS does not occur during encounters with the phobic stimulus is rarely effective in reducing phobic fear (Seligman, 1971). This is perhaps not surprising, since the phobic individual has typically encountered the phobic stimulus in the absence of an aversive UCS on many occasions. Still, the fear continues. For this reason, Seligman (1971) and others refer to phobic fear as a noncognitive or irrational reaction that is fundamentally different to conditioned fear in the laboratory.

McNally (1987) has argued that phobic avoidance can be seen as a rational reaction since it may be motivated by the expectation of becoming anxious in the presence of the phobic stimulus. Though this may be true, it does not deny the observed irrationality of phobic fear. Seligman's (1971) point is that phobic fear continues to be attached to stimuli which have frequently been encountered without an aversive UCS. This, he proposes, is a fundamental difference between phobic fear and conditioned fear, since the later readily extinguishes in CS-alone trials. McNally (1987) counters by arguing that phobic fear "is involuntary and therefore the standards of rationality do not apply" (p. 297). He suggests that phobic fear is therefore better described as nonrational rather than irrational. This play with words, however, seems to miss Seligman's (1971) point. Call it what you will, phobic fear does not reduce when it is clear that a UCS will not occur. In contrast, conditioned fear in the laboratory does. This remains a fundamental difference between the two, as others have recognized ${ }^{1}$ (e.g., Clarke \& Jackson, 1983).

Another potent objection to the general-process learning account relates to the distribution of phobias. According to Pavlov's (1927) view of conditioning, any stimulus, given contiguous pairings with an aversive UCS, may become a CS. Moreover, given equal physical intensity, all stimuli should be equally likely of becoming a CS. In relation to phobias, this principle is expounded most clearly by Wolpe and Rachman (1960). They state, "Any 'neutral' stimulus, simple or complex, that happens to make an impact on an individual at about the time that a fear reaction is evoked acquires the ability to evoke fear subsequently" (p. 145, emphasis added). The traditional conditioning view of acquisition therefore gives no special status or significance to the phobic stimulus. Anything, and everything, may and should become a phobic stimulus given aversive pairings. This principle has been called the equipotentiality premise (Seligman, 1971).

However, as Seligman (1971) points out, there are two characteristics of the distribution of phobias that seem to contradict the equipotentiality premise. First, common

\footnotetext{
${ }^{1}$ It must be acknowledged that clinical phobias, being more intense than analogue fears in the laboratory, may logically require more corrective information for anxiety reduction to occur. However, it should be remembered that even intensive cognitive therapy, without exposure, has often failed to reduce anxiety in clinical studies (see Marks, 1987).
} 
phobic stimuli comprise only a small set of stimuli. While there is no agreement over the exact number, lists of common phobias rarely exceed 50 stimuli. While this may seem an impressively large number, when measured against the number of potential stimuli, it seems small indeed. Clarke and Jackson (1983) make this point in reference to their so-called "phobic fraction." If one places the number of common phobic stimuli in the numerator, and all these plus all other stimuli in the denominator, the resulting fraction is infinitely small - too small, they argue, for the general-process learning account of the acquisition of phobias. If all stimuli may become phobic stimuli, the phobic fraction should approximate one, rather than zero.

The second aspect of the distribution of phobias that is problematic for the traditional learning account relates to the nonarbitrary nature of the limited set of phobic stimuli. Not only is the set small, but it appears to consist primarily of objects and situations that represent serious dangers to pretechnical rather than modern man. Objects associated with pain in recent times do not seem to become phobic stimuli often enough. Seligman (1971) writes, in a now famous and often cited quotation,

Agoraphobia, fear of specific animals, insect phobias, fear of heights, and fear of the dark ... are relatively common phobias. And only rarely, if ever, do we have pajama phobias, grass phobias, electric-outlet phobias, hammer phobias, even though these are likely to be associated with danger in our world." (p. 312)

Rachman (1977) finds support for this view in epidemiological surveys and anthropological observations which question the assumption that all stimuli are equally likely to become phobic stimuli. For example, he notes that Agras et al. (1969) found the prevalence of snake fear to be nearly two times the prevalence of dental fear and five times as common as fear of injections, despite the fact that contact with the dentist and injections are far more frequent, and more likely to be associated with painful episodes. Such findings seem difficult to reconcile with the general-process learning view and, not surprisingly, the distribution of phobias has been one of the most frequently raised objections to the model (Clarke \& Jackson, 1983; Eysenck, 1979; Gray, 1971, 1979; Rachman, 1977; Seligman, 1971).

Some supporters of the conditioning approach argue that contemporary conditioning theory can account for these distribution anomalies. For example, Levis (1979) examines Seligman's (1971) concern about the rarity of phobias of electric outlets and hammers largely in terms of the phenomenon of latent inhibition. He argues that both stimuli are frequently encountered throughout life in nonaversive ways, thus reducing the likelihood of conditioned fear if a subsequent aversive pairing occurs. Furthermore, he points out that early discrimination training is frequently given on how to use such objects in order to avoid pain.

Though it appears that such an account can explain the rarity of some phobias, it does not appear to be a comprehensive explanation. For example, how many individuals have had frequent painless encounters with injections prior to an initial pairing with pain? Moreover, how many have had discrimination training that enables them to experience injections in a painless way? Surely, there are few more commonly encountered stimuli that are more highly correlated with pain. Thus, the rarity of needle phobia, and others like dental phobia, compared to snake and spider phobia is an embarrassment for contingency and contiguity accounts of Pavlovian conditioning alike. Furthermore, how many of us have not frequently experienced water, heights, enclosed spaces, birds, and so on, in safe ways? Does nonreinforced exposure with these stimuli similarly retard subsequent fear conditioning? If so, why are these phobias common? 
Clearly, then, taking refuge in such explanations as latent inhibition cannot save the Pavlovian account. It does not challenge the obvious nonarbitrary nature of the limited set of phobias. While latent inhibition may explain the rarity of some phobias, it does not explain why the majority of common phobias can be so readily related to past long-standing dangers to the species. The selective nature of phobias is difficult to deny and remains a problem for the general-process view of acquisition.

In sum, there are several problems for the traditional conditioning account of phobic onset and maintenance. The persistence, resistance to corrective information, and selective nature of phobias are genuine problems for the Pavlovian explanation. Other cogent criticisms have also been offered, but will be reviewed later since they attack the original conditioning approaches as well as subsequent revisions that have yet to examined in the present paper. At this point, having established some difficulties for the general-process conditioning approach, attention will turn to the reformulated conditioning account offered by Seligman (1971) to specifically deal with these difficulties.

\section{PREPAREDNESS: A CONDITIONING REFORMULATION}

Seligman $(1970,1971)$ proposed that the observed differences between conditioned fear in the laboratory and phobic reactions were due to the arbitrary choices of CSs and UCSs that laboratory workers had been using. In a search for general laws of learning, researchers since Pavlov had used arbitrary sets of events, such as a click paired with meat, so that the emerging laws would be uncontaminated by the idiosyncratic past experiences of the animal or by the biological characteristics of his species. Seligman (1971) saw this as a dangerous methodological practice, proposing that the emerging principles may be peculiar to arbitrary events arbitrarily linked. He argued that animals and humans do a great deal of learning about contingencies which their ancestors had faced for eons, and suggested that this learning may be different from the learning of the novel contingencies that researchers were exclusively examining in the laboratory:

Not only do birds learn to turn wheels for grain, which their ancestors never did, but they also learn to migrate away from the North Star in the fall (Emlen, 1970), a contingency their ancestors faced before them. Not only do humans learn to fear crossing busy streets, but also to fear the dark. All this learning may not be the same. (Seligman, 1971, p. 313, emphasis in original)

Seligman (1970, 1971) proposed that the rate of acquisition of contingencies repeatedly faced by generations of a species may become influenced by natural selection. If acquisition of a contingency meant the difference between life and death, then individuals who quickly acquired it would be more likely to survive, reproduce, and thereby pass on their genetic information to the next generation. If this genetic information influenced the likelihood of the offspring quickly acquiring the same contingency, and the adaptive value of the contingency to the species remained, then the quick acquirers would come to dominate according to Darwin's principle of natural selection. Individual variation in the rate of acquisition would continue, but members of the species, on average, would come to acquire the contingency more readily than their ancestors. Seligman called the acquisition of such a contingency "prepared" learning, and contrasted it to the "unprepared" learning that was typically being examined in the laboratory. He suggested that in addition to being rapidly 
acquired, and in further contrast to unprepared learning, prepared learning could be acquired despite degraded input, would be resistant to extinction, insensitive to cognitive factors, and selective with regard to the conditional stimulus (Seligman, 1971).

Seligman (1971) saw phobias as model examples of prepared learning since they involved fears of objects and situations that seemed to represent long-standing dangers to our pretechnical ancestors. In contrast, animal fear conditioning in the laboratory had involved CSs of minimal evolutionary significance (e.g., tones, lights), and were seen as instances of unprepared learning. Moreover, the model predicted the very difficulties that, according to Seligman (1971), had plagued the general-process account of the etiology of phobias. That phobias often developed quickly and easily, were persistent despite nonreinforced exposure, were insensitive to corrective information, and selective with regard to stimulus, were problems for the general-process learning view that seemingly disappeared with the addition of the preparedness dimension. Not surprisingly then, the dimension of preparedness came to be seen by many as the salvation of the classical conditioning account of phobias.

Seligman (1971) saw further evidence for the preparedness account of phobias in several reported failures to demonstrate fear conditioning in children in the years following Watson and Rayner's (1920) original demonstration with Albert. Pointing to the work of Bregman (1934) and English (1929), Seligman (1971) claims that they failed to demonstrate fear conditioning when using CSs that were more evolutionary"neutral" (e.g., common household objects, wooden blocks) than the furry rat used by Watson and Rayner (1920). As has been already pointed out, however, methodological shortcomings in these studies are sufficient to explain any failures in conditioning. Fortunately, during the last two decades, a body of research more directly testing the preparedness account of phobias has appeared, beginning with the work of Ohman and his colleagues. Most support has come from their consistent finding that electrodermal responses conditioned to evolutionary-fear-relevant stimuli (e.g., snakes, spiders, angry faces) are more resistant to extinction than responses conditioned to evolutionary-fear-neutral stimuli (e.g., houses, flowers, mushrooms) (e.g., Ohman \& Dimberg, 1978; Ohman, Eriksson, \& Olofsson, 1975; Ohman, Erixson, \& Lofberg, 1975; Ohman, Fredrikson, Hugdahl, \& Rimmo, 1976). Hence, in regard to extinction, these studies suggest that prepared fear-conditioning appears to be more like phobic reactions than does unprepared learning.

Unfortunately, attempts by other researchers to replicate the resistance-to-extinction effect have met with mixed success. Lang and his colleagues failed to find the resistance-to-extinction effect in four initial attempts (Hodes, 1981). This failure may in part have been due to their choice of UCS. Rather than shock, a loud aversive noise was used as the UCS in each of the failed attempts. Hodes (1981) concluded that the UCS may need to be tactile (e.g., electric shock), since it better simulates the UCS delivered by a snake or spider (i.e., bite). This hypothesis was supported by Cook's (1983) work, which directly compared the effectiveness of shock and noise as a UCS in obtaining the resistance-to-extinction effect. In only the shock condition was the resistance effect found. However, McNally and Foa (1986) and others have failed to obtain the resistance-to-extinction effect despite using shock as the aversive UCS. Thus, Hodes' (1981) explanation cannot account for all of the failures to date. At this point, then, as Marks (1987) concludes, though the majority of studies have found the resistance effect, it does appear to be a somewhat fragile and elusive finding.

Of greater concern to the preparedness account has been the difficulty in obtaining the other predicted differences between prepared conditioning and unprepared conditioning. First, though prepared learning is defined as learning rapidly or easily 
acquired, it has proved difficult to show differences in rates of acquisition of conditioned responses between evolutionary-fear-relevant and fear-neutral stimuli. Researchers, including the Ohman group in Sweden, have typically failed to find speed of acquisition differences (Marks, 1987). This may have been due in part to the use of skin conductance as the response measure in most studies. It has been suggested that the rapid acquisition of electrodermal responding produces a ceiling effect that obscures fear-relevance effects (Hodes, 1981; Marks, 1987). Use of another response may lead to more promising results in the future. Some support for this comes from several studies in Lang's laboratory which have found faster acquisition of a conditioned rise in heart rate to fear-relevant stimuli than to fear-irrelevant stimuli (Cook, Hodes, \& Lang, 1986, cited in Marks, 1987).

Unfortunately, other tests of the ease of acquisition hypothesis have not supported the preparedness account. Seligman (1971) suggests that prepared associations will be acquired despite degraded or unfavourable learning conditions. Yet, degraded input (e.g., long interstimulus intervals) has been found to attenuate conditioning to both fear-relevant and fear-irrelevant CSs (Hugdahl \& Ohman, 1980). In sum, there is very little experimental support for the ease of acquisition hypothesis (McNally, 1987).

With regard to the irrational or noncognitive nature of phobic responses, Ohman and his colleagues have argued that electrodermal responses conditioned to evolutionary-fear-relevant stimuli should persist even when the subject is told that the UCS will no longer be presented. Consistent with this hypothesis, Ohman and colleagues report that telling subjects that the UCS would no longer be delivered led to the reduction of responses to fear-irrelevant stimuli but not to fear-relevant stimuli (Hugdahl \& Ohman, 1977; Ohman, Erixson, \& Lofberg, 1975). Such resistance to instructed extinction with fear-relevant stimuli even persisted when the shock electrodes were removed from the subjects. Again, however, there have been several reported failures to replicate this effect (e.g., Cook, 1983, Experiment 2; Dawson, Schell, \& Tweddle-Banis, 1986). As Ohman, Dimberg, and Ost (1985) and McNally (1987) note, there is no obvious explanation for this inconsistency. Again, the effect appears to be a fragile one.

In sum, laboratory findings have produced only limited support for the preparedness account of phobias. Moreover, it is not clear at this point that any of the supportive findings require the preparedness explanation. Various accounts focussing on ontogenetic preparedness (Delprato, 1980), animateness (Carr, 1979), latent inhibition (Carr, 1979; Levis, 1979), prior fear levels (McNally \& Foa, 1986; McNally \& Reiss, 1984), CS salience (Ohman et al. 1976), CS prepotency (Marks, 1987), expectancy biases (Davey, 1992), and stimulus significance (Maltzman \& Boyd, 1984) have been proposed as alternative explanations of the data. Though many of these have not been supported to date (see further, McNally, 1987), some still require adequate testing.

Of further concern is the question of how much of an analogue of human phobias the Ohman studies have been. Due to ethical concerns in the use of human subjects, the intensity of the UCSs have been typically set by the subjects themselves, and they are asked to do so at a nonpainful level. Thus, the studies may have involved only mild levels of fear, if any fear at all. Too few studies have bothered to examine subjective levels of fear and avoidance (Marks, 1987), and too few evolutionary-fear-relevant stimuli have been used to date. In sum, at present it is difficult to consider this laboratory work as a comprehensive account of human phobic reactions.

More problems confront the preparedness account upon turning from the laboratory to the clinic and examining phobic disorders in terms of the predictions of the model. First, clinical phobias related to evolutionary-fear-relevant stimuli (e.g., 
snakes, heights) should have been more quickly acquired and prove more difficult to treat than evolutionary-neutral phobias (e.g., cars). However, preparedness has not been found to relate to acquisition (De Silva, Rachman, \& Seligman, 1977; Merckelbach, Van Den Hout, Hoekstra, \& Van Oppen, 1988; Zafiropoulou \& McPherson, 1986), and in two studies has not been found to relate to treatment (De Silva et al., 1977; Zafiropoulou \& McPherson, 1986), a fact which seriously weakens the clinical utility of the concept. However, one recent study has found that prepared clinical phobias, when compared to unprepared clinical phobias, are resistant to behavioural treatment (Merckelbach et al., 1988). The reasons for differences with previous findings may depend upon differences between treatments and the measures used to indicate gain. This issue clearly needs to be resolved. At this point, however, there is little support for the preparedness hypothesis in clinical cases. More research examining predictions of preparedness in clinical groups is needed.

The most significant problem facing Seligman's account, however, relates to the need for direct conditioning trials for onset. It must be remembered that, as a modified conditioning account, Seligman (1971) claims that at least one CS-UCS trial, or a higher-order conditioning trial, is required for the aquisition of any phobia. On this claim, more than any other perhaps, the account must fall as a comprehensive explanation of phobic onset. For, in many clinical cases, traumatic conditioning episodes do not appear to have preceded onset (Clarke \& Jackson, 1983; Menzies \& Clarke, 1993a, 1993b). While differences in methodology and the phobias being investigated have led to varying estimates of the number of conditioned cases, it is now widely accepted that for many patients no associative trauma occurred prior to onset. Even in studies that are generally supportive of the direct-conditioning model, as many as $40 \%$ of subjects could not recall aversive associative-conditioning procedures at onset (Ost 1991; Ost \& Hugdahl, 1985; Wolpe, 1981). Other researchers suggest this figure may be much higher. Lazarus (1971), for example, reports that $50 \%$ of patients presenting with specific irrational fears had never even encountered their feared object or situation, let alone suffered an aversive UCS in its presence. Only $2 \%$ recalled traumatic conditioning at the onset of their concerns. Menzies and Clarke (1993a) have recently reported that of 50 clinical cases of childhood water phobia, only one parent could recall a conditioning event at onset. Essentially similar findings have been obtained in several reports on fear of spiders. Kleinknecht (1982) assessed the acquisition of fear in members of a tarantula interest group, noting that "salient by its omission was any mention that could be construed to be direct traumatic experience involving a painful bite which led to fear" (p. 440). Similarly, Davey (1992) could find only one of 118 undergraduates who reported a truly arbitrary aversive experience of the kind proposed by traditional conditioning theory (a spider appeared while a subject was being sexually harassed by her boss). Finally, Jones and Menzies (1994), using the only origins questionnaire with high levels of demonstrated interrater reliability and construct validity, found no spider-fearful undergraduates with conditioning histories in their sample of 20 . The only subjects that had been bitten in this latter study were four nonfearful controls. Even given the retrospective nature of these reports, such findings remain an embarrassment to any direct classical-conditioning account, and are as damaging to preparedness as they are to the general-process view that it sought to replace. Clearly, all direct classical-conditioning accounts must fall, on this point alone, as comprehensive models of the onset of phobias. 


\section{THE THREE PATHWAYS ACCOUNT}

It was largely the recognition that many phobics reported no history of direct Pavlovian conditioning that led Rachman (1977) to posit his three pathways account of fear development. In addition to direct classical conditioning, Rachman (1977) posited two indirect processes of acquisition, namely vicarious learning and the transmission of information/instruction.

That vicarious or observational experience may result in the acquisition of intense fears and phobias is suggested from a variety of sources. First, Rachman (1977) claims support from uncontrolled war-time observations of combat airmen who acquired fears after observing the intense fear reactions of a crew mate (e.g., Grinker \& Spiegel, 1945). Second, in several studies some phobic patients have retrospectively attributed the onset of their concerns to vicarious events (e.g., Fazio, 1972; Rimm, Janda, Lancaster, Nahl, \& Dittmar, 1977). Third, several experiments have successfully conditioned autonomic responses to neutral stimuli as a result of observational experiences (e.g., Bandura \& Rosenthal, 1966; Brown, 1974; Craig \& Lowery, 1969; Hygge, 1976; Kravetz, 1974). Finally, Rachman claims support for the vicarious position in studies showing that children often share their parents' fears (Bandura, Blanchard, \& Ritter, 1969; Hagman, 1932; John, 1941; Windheuser, 1977).

Any relationship between parents' and children's fears may be also due to the informational/instructional mode of onset. Other support for the notion that fear can be acquired through the transmission of information comes from experimental research with human electrodermal conditioning. Many researchers, beginning with Cook and Harris (1937), have found increases in the magnitude and frequency of skin-resistance responses to a cue after informing subjects that the cue would be followed by shock. That is, actual pairing with shock is not necessary to bring about fear. Finally, in several reports a small number of patients have attributed their phobic concerns to the transmission of information or instructions (e.g., Rimm et al., 1977). From a variety of sources, then, it appears, and is now universally accepted, that phobias may arise following indirect learning as well as direct conditioning procedures.

Having proposed three pathways to onset, Rachman (1977) went on to speculate on the relationship of the onset modes to severity, individual response patterns, and treatment. In reference to severity, he suggests that phobias acquired indirectly, through the information and vicarious modes, are more likely to be mild than severe. The common, less intense, and everyday phobic concerns and fears are seen to be predominantly due to indirect acquisition. In contrast, intense, severe phobic concerns that are likely to appear in the clinic are seen to be more likely due to classical conditioning. That is, fears acquired through classical conditioning are more likely to be severe than mild.

Ost and Hugdahl (1985) find some support for this hypothesis in comparing their studies of clinical phobic patients with studies of the origins of analogue cases. In severe clinical groups of animal phobics, social phobics, claustrophobics (Ost \& Hugdahl, 1981), agoraphobics (Ost \& Hugdahl, 1983), and blood and dental phobics (Ost \& Hugdahl, 1985), they report the proportion of conditioned cases to be significantly higher than the indirect ways of acquisition. In contrast, they refer to studies of analogue cases involving lower levels of fear (e.g., Fazio, 1972; Kleinknecht, 1982; Murray \& Foote, 1979; Rimm et al., 1977), in which indirect acquisition seemed to predominate. Hence, they argue, similarly to Rachman (1977), that classical conditioning predominates in clinical cases, whereas indirect acquisition is responsible for mild, everyday concerns. 
Other explanations for differences between these studies can of course be found. As McNally and Steketee (1985) point out, differences in definitions of what constitutes a conditioning event may have led to dramatically different data across these and other studies. Many have criticised Ost and his colleagues for equating any frightening or traumatic incident with classical conditioning, even when no identifiable UCS can be found (Marks, 1987; Mattick, 1987; Menzies \& Clarke, 1993a, $1993 \mathrm{~b})$. This may lead to the misclassification of a substantial number of cases and an overestimate of the number of classical conditioning cases (Menzies \& Clarke, 1993a). As already stated, other reports with clinical cases have frequently found much lower percentages of conditioning cases (e.g., Kleincheht, 1982; Lazarus, 1971; Menzies \& Clarke, 1993a, 1993b).

It should also be noted, in reference to Rachman's hypothesis of the relationship of origins to severity, that within each of the Ost and Hugdahl series of studies, it has been rare to find the predicted differences. Within clinical groups of social phobics, claustrophobics (Ost \& Hugdahl, 1981), agoraphobics (Ost \& Hugdahl, 1983), blood and dental phobics (Ost \& Hugdahl, 1985), and blood and injection phobics (Ost, 1991), classically conditioned cases were not found to be more severe than indirectly acquired cases. Only in a mixed group of animal phobics was the hypothesis supported (Ost \& Hugdahl, 1981). It is possible that such failures may be due to the use of a restrictive range of severity associated with patient groups. Use of a broader range of levels of severity may be needed to find such differences. Furthermore, for the methodological reasons already raised, these results may be of questionable validity. Clearly, more research is needed on this issue. Recently, Menzies and Clarke (1993b) have again failed to support Rachman's hypothesis with a large sample of height-fearful students. On several severity measures, classically conditioned cases were not found to be more severe than indirectly acquired cases.

In a second hypothesis, Rachman (1977) suggests that conditioning cases will be predominantly associated with the physiological and behavioural response systems, whereas phobias arising through the two indirect modes are more likely to be associated with the subjective component. Again, most of the work on this question comes from Ost and his colleagues. On the whole, they have failed to support Rachman's hypothesis. They found no relationship between the mode of acquisition and the anxiety-response patterns in clinical groups of animal phobics, social phobics (Ost \& Hugdahl, 1981), agoraphobics (Ost \& Hugdahl, 1983), blood and dental phobics (Ost \& Hugdahl, 1985), and blood and injection phobics (Ost, 1991). Only in claustrophobic patients have they reported any supporting data for the Rachman hypothesis. In this group, patients with a "conditioning" onset had a larger physiological reaction than the indirect onset cases (Ost \& Hugdahl, 1981). Further, the indirect group had a larger subjective reaction than conditioning cases. However, contrary to Rachman's hypothesis, the indirect group also had the strongest behavioural reaction. Unfortunately, all of these findings must be tempered by the methodological queries previously raised over the method of classifying patients into onset modes in these studies. More research is needed on this question, particularly in relation to other phobias.

Taking the pathways account further, Wolpe, Lande, McNally, and Schotte (1985) have speculated that fears based on information require cognitive solutions whereas fears based on conditioning require deconditioning procedures. Clearly, there is evidence that anxiety responses can be acquired by classical conditioning and eliminated by extinction-like procedures (Wolpe et al., 1985). Further, there is evidence that some anxiety responses based on erroneous cognitions can be eliminated by cognitive 
corrections (e.g., Bridger \& Mandel, 1964; Ohman \& Hugdahl, 1979). However, whereas matching of individual response patterns to treatment has proved popular with researchers, there is a lack of controlled investigations demonstrating the supposed advantage of matching origin to treatment type. Ost (1985) reports on a post hoc analysis of the relationship between acquisition modes and different treatments for clinical phobias. Averaged across six phobic types, Ost finds some support for Wolpe's hypothesis. Among patients with a conditioning acquisition, behaviourally and physiologically focused treatments led to significantly larger improvements than did the cognitively oriented treatment. However, contrary to Wolpe et al.'s (1985) prediction, the behavioural methods rather than the cognitive approaches also yielded the largest improvement in patients of the indirect acquisition. Again, several limitations in this analysis must be noted. First, the analysis involved a post hoc combination of studies that had been designed to examine other issues. Second, it involved the averaging of data across six types of phobias. Third, as with previous studies, it relied on a questionable method of allocation to onset type.

Before leaving Rachman's pathways-to-fear model, it should be noted that it has been largely endorsed by cognitive formulations of anxiety, proposing that expectancies of harm mediate anxiety responses. For these cognitive theorists (e.g., Bolles \& Faneslow, 1980, Carr, 1979; Davey, 1992; Reiss, 1980, 1991) agree that aversive respondent conditioning is not necessary to produce fear, since an expectation of danger can develop without direct trauma. Carr (1979) notes that both observational learning and instructions can provide information that may contribute to expectancies of harm and therefore lead to fears and phobias. Such expectancy accounts of phobias, though popular in the current cognitive climate, are not without their problems. First, though some suggestive work exists, there have been relatively few demonstrations of distorted expectancies of danger among phobic patients. Second, even if distorted danger expectancies are found, they must be shown to correlate with resultant levels of anxiety. When the correlation of danger expectancies with phobic anxiety is examined, it has, in some studies, been found to be poor (e.g., Williams \& Watson, 1985). Third, it is difficult to understand how expectancies of danger come to mediate phobic fear of seemingly innocuous events. What danger is perceived by a cockroach phobic suffering intense anxiety while simply looking at a photograph of the insect? In sum, though some suggestive work exists, at this point it is difficult to unequivocally support the expectancy models of fear. Further research on the potential mediating role of danger expectancies is clearly needed.

What is clear from the above discussion is that Rachman's pathway model has made a significant contribution to our understanding of the etiology of phobias. It has freed us from the restrictive shackles of direct conditioning accounts and opened the door to other origin modes and the possibility of better patient-treatment matching. However, it should be recognised, though it has not been in some quarters, that it cannot be regarded as explaining all possible modes of the onset of phobias. First, many case histories simply cannot be easily placed into one of Rachman's three categories. For many patients, the onset of their concerns seems to occur with no previous direct or indirect trigger (Clarke \& Jackson, 1983; Menzies \& Clarke, 1993a, 1993b). Similarly, it has been claimed that traumatic associative triggers are not needed for the onset of the ontogenetic parade of fears we see in early childhood (Gray, 1971), and the fear reactions of many animal species (Tinbergen, 1951). Thus, it is being increasingly claimed from writers of various perspectives including the ethological (Tinbergen, 1951), clinical (Marks, 1969, 1987), and experimental psychological (Clarke \& Jackson, 1983; Menzies \& Clarke, 1993a,1993b), that fears and phobias may 
arise without any direct or indirect associative learning. The evidence and theory of this nonassociative perspective will now be examined.

\section{THE NONASSOCIATIVE PERSPECTIVE}

The notion that fear can be aroused by stimuli without previous direct or indirect associative learning is not a new one. It must be remembered that Watson's original classical conditioning model logically requires at least one UCS which is said to inherently elicit fear or distress to which neutral CSs can become paired. In fact, Watson (1924) posited three such stimuli, namely loud noise, pain, and sudden loss of support.

Of course, the idea of fear in the absence of prior learning did not originate with Watson. Much earlier, Charles Darwin had suggested it in relation to several childhood fears, and gone further in positing its cause. In 1877, after observing his 2-year-old son's fear of caged zoo animals, Darwin asked, "May we not suspect that . . f fears of children, which are quite independent of experience, are the inherited effects of real dangers... during savage times" (Darwin, 1877, cited in Marks, 1987, p. 112). Thus, he proposed that by the process of natural selection, our ancestors developed fear of many consistently dangerous situations. We have already reviewed one major Darwinian-based account of phobia onset, namely Seligman's preparedness theory. However, unlike Seligman's account, Darwin's original conception states that no aversive experience of the stimulus is needed for the acquisition of fear. Fear is said to be "independent of experience," and can be regarded as either innate (i.e., present at birth) or requiring only development of the nervous system to a particular stage (i.e., maturation).

While some seem to endorse this view of many fears and phobias without change (e.g., Gray, 1971), most contemporary theorists argue that Darwin's notion of fear that is "independent of experience" is too strong a claim. Marks (1987), for example, argues that appearance of a predictable series of fears at set ages in childhood across a variety of cultures "reflects maturation under genetic control during interaction with the environment" (p. 109, emphasis added). He points out that the expression of a genetic program depends on the environment, and that changes in the environment may change the resulting phenotype from fertilization onward. For example, the fear of moving objects shown by very young chicks can vary with the experience of illumination that occurred while in the egg (Dimond, 1966; Salzen, 1979). Schneirla (1972) anticipates Marks, emphasizing, as the determinants of fearful behaviour, the complete developmental history of the organism in which genetic and experiential factors both play a role. He denies the existence of "innate" and "learned" as separate entities. Whereas the specifics of these and other theorists differ in the influence they give the environment, what is being claimed by these modern Darwinian-based accounts is that fear of some stimuli can develop in the absence of any previous experience with the feared stimuli. No direct or indirect traumatic pairing with the feared stimulus is required, and neither is negative information. Though some background experiences may be necessary (e.g., illumination in the egg), aversive associative learning is not.

An exhaustive review of the many stimuli in many species to which "unlearned" fear has been claimed is beyond the scope of this paper. What will be reviewed are the more commonly cited cases of fear that can be used to support the nonassociative perspective.

Perhaps most frequently cited, and claimed by some to be the best evidence for the genetic basis of fear (e.g., Hetherington \& Parke, 1982), is the fear of conspecific threat seen in infant rhesus monkeys. Sackett (1966) found selective sensitivity of rhesus monkey infants reared in isolation to conspecific threat displays at ages 2.5 to 4 months. In daily test sessions, slides depicting monkeys in various poses were project- 
ed onto a screen. In some sessions, the infant could turn on the slides by lever-pressing. During the 9 months of testing, there was little distress shown to any of the pictures except those of threat. Starting at 2.5 months, and peaking at 3 months, all monkeys became markedly disturbed, exhibiting fear, withdrawal, and rocking, whenever pictures of threatening monkeys appeared on the screen. A drop-off in lever-presses to turn on the threat slides occurred during the same period. Lever-presses to other slides continued to increase. Thus, due to their isolated rearing, it has been claimed that fear of conspecifics in rhesus monkeys develops in the absence of traumatic direct or indirect conditioning episodes. From an evolutionary point of view, it is easy to speculate on the adaptive value of a fear of conspecific threat. For, in many species, the killing of conspecifics is commonplace (Marks, 1987). Ignoring threat displays may result in the death of the infant.

Conspecifics do not have to be threatening to cause fear. Just being unknown can elicit anxiety. Fear of strange conspecifics occurs in birds (Gray, 1971), chimpanzees (Hebb, 1946), and many other mammals including man (Marks, 1987). It does not require aversive experience with strangers to develop but readily appears in virtually all cases of many species for set periods following the same pattern. In spite of different child-rearing practices, human infants display this phenomenon at similar ages in the United States, United Kingdom, Guatemala, and among the Kung Bushmen and Hopi Indians (Dennis, 1940; Smith, 1979). It develops from ages 4 to 9 months, peaking around 12.5 months, before declining in the second year. More support for the genetic basis of the fear comes from research finding greater concordance of onset age (e.g., Freedman, 1965) and a greater similarity in expression (e.g., Plomin \& Rowe, 1979) of stranger fear between identical than fraternal twins. As with conspecific threat, it is easy to speculate on the adaptive value of this fear. As already stated, the killing of conspecifics in many species is common. Further, this killing is often of strange, unknown conspecifics, especially youngsters and infants (Marks, 1987). Fear of strangers may have evolved as protection against this abuse.

Closely related to stranger fear is separation anxiety, which occurs in many species including a host of mammals, and nearly all primate species studied (Kraemer, 1985; McKinney, 1985; Mineka, 1982). Human infants are likely to cry at their parent's departure from 8 to 24 months (Kagan, Kearsley, \& Zelazo, 1978; Smith, 1979). Again, this occurs despite different child-rearing practices in a variety of countries including the United States, Guatemala, and Israel (Kagan et al., 1978). It is seen in children with Down's syndrome, in the blind (who recognise the absence of their guardian by sound), and is the same if the guardian is male or female, or if the child was reared at home or in day care (Marks, 1987). It is unrelated to the amount of previous time spent with the guardian and, more importantly, is unrelated to past aversive experiences during separation (Bowlby, 1975; Clarke \& Jackson, 1983; Marks, 1987). Again, it is easy to speculate on the adaptive value of the fear. Bowlby (1975) and Marks (1987) have argued persuasively that separation from a caretaker increases the likelihood of coming to grief from a number of sources in a number of species.

So great a threat may separation have been to our primate predecessors that many theorists see the protective clasping reflex known as the Moro or embracing reflex, that is present at birth in human infants, as a remnant of primate behaviour when the newborn had to clasp and cling to the mother in order to avoid separation from the troop (e.g., Robeck, 1978). If a human infant's head is dropped slightly but abruptly, the arms are thrown out and the neck and legs are extended. The infant may then cry and bring the arms together in a clasping motion, sometimes flexing the thumb in a grasping motion. This embracing reaction to a sudden loss of support was named 
after its discoverer as the Moro reflex (Moro, 1918) and was recognised by Watson (1919) in his early studies of the newborn. As already stated, Watson saw loss of support as one of only three stimuli which inherently led to fear or distress (i.e., unconditional fear stimuli).

Of course, the protective value of the Moro reflex is open to other interpretations. Perhaps a more plausible account is that it protects the infant from the dangers of falling per se, rather than subsequent threats of separation from the group. This is the significance seen in the Moro reflex by Walk and Gibson (1961). They argue that, for infant terrestrial animals, loss of support means falling, and falling, for most, means potential injury or death. They see the clinging and grasping of the Moro as a protective device to reduce the likelihood of falling and subsequent injury, and see loss of support as the basis of fear of heights.

According to Walk and Gibson (1961), the embracing reflexive response to loss of support is not our only protection from the injuries associated with falling. They argue that evolution has also equipped us with the ability to detect, by vision, sites of potential loss of support where the ground drops to a lower level making an edge or cliff. Due to natural selection, they propose that fear and avoidance of such sites, without prior aversive conditioning, will develop in many species by the age at which selfproduced locomotion occurs. To test this notion, they developed the now famous apparatus known as the "visual cliff." After testing many different species up and down the phylogenetic scale, they have, in the eyes of many, shown fear and avoidance of heights to be the best example of the development of fear in the absence of aversive associative learning. Given its importance to the nonassociative account, this research will be reviewed in some detail.

The visual cliff consists of a thin board laid across a large sheet of glass which is supported at varying heights above the floor. On one side of the board, a sheet of patterned material is placed flush against the underside of the glass. On the other side, a sheet of the same material is laid upon the floor. The latter side thus becomes the visual cliff. Though the board width, thickness, and height of the glass varied in Gibson and Walk's various studies (in order to accommodate different species), the apparatus remained, in its essentials, as described above.

In their original work with human subjects, Gibson and Walk (1960) tested 36 infants ranging in age from 6 months to 14 months. The procedure began by placing the infant on the centre board. The child's mother would then call from the deep side and the shallow side alternately. $A l l$ of the 27 infants tested who moved off the centre board crawled onto the shallow side at least once; only 3 of them ever crawled onto the deep "cliff" side (Gibson \& Walk, 1960). Many infants crawled away from their mother when she called to them from the deep side. Others would pat the glass but, despite the tactual evidence that the "cliff" was in fact a solid surface, would refuse to cross it. Still others would peer down through the glass on the deep side and then back away. Others simply cried (Gibson \& Walk, 1960).

Findings with other terrestrial species were largely consistent and equally dramatic. Due to their early self-produced locomotion, chicks, kids, and lambs could be tested on the first day of life as soon as they could stand. No chick, goat, or lamb tested ever stepped onto the glass on the deep side, even at one day of age (Gibson \& Walk, 1960). When lowered onto the deep side, kids and lambs would initially refuse to put their feet down. This was followed by the adoption of a posture of defense, the front legs becoming rigid and the hind legs limp. From this immobile state they would often leap in the air to the apparent safety of the centre board, rather than walk on the glass. Despite repeated placements on the deep side, and therefore repeated 
experience of the tactual solidity of the glass, goats and lambs never learned to function on the deep side (Gibson \& Walk, 1960). Similar findings with cats and land turtles were obtained, and other researchers have extended the list to include dogs, pigs, and neonatal monkeys to name but a few. Indeed, there are few fears that appear more consistently in terrestrial animals. Unlike land-dwelling animals, aquatic species such as ducks and turtles, who have little reason to fear a perceived drop, readily cross onto the deep side (Emlen, 1963; Routtenberg \& Glickman, 1964).

Walk and Gibson (1961) concluded that, in a variety of terrestrial species, fear and avoidance of heights is innate and appears by the time the infant is locomotive. However, as we have been urged by more recent writers, to deny the role of experience and the environment in the development of fear is fraught with danger. Subsequent research, not surprisingly, has shown that certain background experiences may be necessary for the development of avoidance of the visual cliff. The most notable of these is self-produced locomotion. Despite some controversy (cf. Bertenthal \& Campos, 1984; Campos, Hiatt, Ramsay, Henderson, and Svejda, 1978; Richards \& Rader, 1983), it now appears clear that previous experience of self-produced locomotion may be necessary for avoidance and fear of the visual cliff to be consistently observed. Bertenthal, Campos, and Barrett (1984) report on various findings supporting this conclusion. Seven-and-a-half-month-old prelocomotive infants showed little cardiac changes indicative of fear when placed on the deep side, whereas locomotive infants of the same age elicit heart rate acceleration. Also, prelocomotive infants given locomotor experience through 40 hours in an "infant walker" showed heart-rate acceleration when placed on the deep side, whereas prelocomotor infants of the same age without "walker" experience did not.

However, it must be emphasised that while self-produced locomotion appears to be important in the development of the avoidance of the visual cliff, previous falls have been found to be unrelated and unnecessary for avoidance to occur (e.g. Scarr \& Salapatek, 1970). That is, while experience seems to play a role in the emergence of this fear, it need not take the form of aversive classical conditioning. Crawling may be important in expanding the infant's perspective by increasing its encounters with new experiences, and seems to speed the emergence of spatial cognition, form extraction, and social communication, as well as fear of heights (Marks, 1987).

The fears examined above do not represent an exhaustive list of those that are believed to emerge in the absence of aversive associative learning. Visual looming, eyespot patterns, various odours, and novelty can produce fear in infants of various species in the first days of life without any prior aversive CS-UCS pairing (see further, Marks, 1987). The case for "unlearned" fear of stimuli representing special evolutionary dangers appears a strong one and, as stated, continues to attract theorists from various perspectives (e.g., Bowlby, 1975; Clarke \& Jackson, 1983; Gray, 1971, 1979; Marks, 1969, 1987; Menzies \& Clarke, 1993a, 1993b; Tinbergen, 1951). Not only does the evidence seem to support it but, according to many, the "unlearned" account is a more plausible explanation than its major Darwinian opponent, namely Seligman's preparedness theory. For, in Seligman's account, as previously explained, at least one painful associative-learning trial is required for acquisition. As already pointed out, this does not accord with the histories of many patients - nor should it, some claim, when considering it from an adaptive Darwinian viewpoint (Clarke \& Jackson, 1983). For, even one aversive associative trial may lead to the death of the individual. Must we really fall from a cliff in order to learn to fear and avoid heights? Bowlby (1975) says no: 
In the past there have been theorists who have postulated that...all stimuli derive their feararousing properties from becoming associated with pain. Not only is the theory false, but a moment's thought shows it to be hardly plausible. As a natural clue to potential danger, the experience of physical pain is in a special category. The clues to which attention has so far been directed are distal clues perceived by the distance receptors . . . By giving warnings while potential danger is still more or less remote, these clues enable an animal or man to take precautions in good time. By contrast ... to await events until pain is experienced may well be to wait too long ... physical pain has the status of last ditch. (p. 171)

Put simply, even a single fall from a great height may lead to the quick demise of a young infant. One learning trial is, in Bowlby's view, often one trial too many.

According to this view, then, given maturational processes and normal background experiences (e.g., illumination in the egg, self-produced locomotion), most members of the species will show fear to a set of evolutionary stimuli on their first encounter (Clarke \& Jackson, 1983). One may fairly ask therefore, of this nonassociative account, why we do not all remain fearful of these stimuli? For example, given our seemingly irrational infant avoidance of the glass covering the visual cliff, why do we not all remain height phobic? Clarke and Jackson (1983) propose that the waning of the fearful response is due to repeated, nontraumatic exposure to the feared object or situation (i.e., habituation). They suggest that poor habituators and those who do not get the opportunity for safe exposure will remain fearful of the stimulus from their first encounter, appearing for treatment at a later age. Some supportive data for this model of onset comes from two recent studies of the origins of clinical cases of childhood water phobia. As early as 1897 , Stanley Hall had suggested that the first experience with water may excite fear (Marks, 1987). The work of Willis (1983) and Menzies and Clarke (1993a) suggests that this initial anxiety may remain and necessitate treatment' many years later. Willis (1983) reported that $48 \%$ of parents of clinical water phobics claimed their child's concern had been present on their first encounter with water and had simply never gone away. Menzies and Clarke (1993a) found the figure to be an even higher $58 \%$. In the latter sample, direct conditioning episodes prior to the onset of fear were reported by only $2 \%$ of parents. Similarly, Jones and Menzies (1994) report that $63 \%$ of their undergraduate spider-fearful sample claimed to have always been afraid. No cases of spider fear were found to originate with direct conditioning, vicarious conditioning, or information/instruction.

In addition to the failure of habituation, Clarke and Jackson (1983) propose that phobias may arise through the process of dishabituation. The unlearned phobic response is not claimed to be eliminated through habituation, but merely subdued. Bowlby (1975) and Clarke and Jackson (1983) argue that periods of extreme difficulty in a person's life may act to raise levels of arousal and lower the threshold for the disha bituation of previously mastered reactions. They describe many cases in which severe interpersonal conflict, certain physiological disorders, and other external stressors have led to the appearance of phobic anxiety to stimuli previously mastered in early childhood (e.g., separation, heights). Menzies and Clarke (1993a) found that $16 \%$ of heightfearful students whose fear developed during a nonconditioning traumatic event claimed to be experiencing a period of severe stress or depression at the time.

\section{CONCLUDING COMMENTS}

The nonassociative perspective, though promising as an account of many phobias, is of course not without its difficulties. First, as with other Darwinian theories, it is based 
on post hoc claims about survival pressures in the distant past, which are all to easy too posit, but difficult to test (Davey, 1992). Second, with human subjects, the predictions of the model can, at times, be difficult to evaluate due to ethical concerns and the practical difficulties in sufficiently controlling the subjects environment. Even so, the growing evidence that fear of many stimuli can originate without aversive conditioning cannot be denied. In human subjects, it appears that aversive associative learning need not be a precipitant of fear of water, heights, spiders, strangers, and separation, to name but a few. To continue to support the associative position as a comprehensive account of phobic etiology in the face of this growing list seems pointless. Of course, this does not mean that the nonassociative model can account for all fears and phobias. The number of fears that can be explained by this etiological model remains to be established. This is essentially an empirical issue and only further research will determine the generality of the model. Clearly, the establishment of this new etiological pathway does not mean that associative learning processes cannot be involved in phobic etiology. Gray (1979) argues persuasively that the conditioning account will always be needed to explain the onset of some cases. For example, he describes a patient's fear of a particular wallpaper that developed after receiving a thrashing in its presence. The nonassociative account does not predict that such associative-learning events cannot precede fear onset. Rather, it is claimed that with many stimuli, associative learning is not necessary for fear onset. Addition of the nonassociative pathway should not be taken to eliminate the possibility of conditioned fears.

The nonassociative account is of great theoretical interest, but also has important clinical implications. The model suggests that an endless search for supposedly "forgotten" traumatic events consistent with the conditioning model may not be warranted for certain phobias. Recent research on acrophobia, for example, has failed to find any relationship between a history of direct or indirect aversive associative events and severity, individual response patterns, or clinical outcome (Menzies \& Clarke, 1994). According to the nonassociative account, this finding is not surprising, since the presence or absence of aversive-learning events may be of little relevance to the appearance of this particular fear (cf. Gibson \& Walk, 1960; Menzies \& Clarke, 1993b). In general, it can be suggested that individualised matching between treatment procedures and mode of onset is not likely to be profitable with the biologically based phobias.

In addition, it is suggested that clinicians should avoid insisting that associativelearning events have occurred in a patient's past and are the crucial determinants of the patient's present fear. Patients carry with them implicit models of the origin and course of their phobia, and these models should be examined by the clinician (Clarke \& Jackson, 1983). Insisting that the patient is wrong in claiming that they have always been afraid, or insisting that they have simply forgotten supposed conditioning events, is not likely to be profitable in therapy. When patient and therapist models of etiology are diametrically opposed, compliance in therapy is likely to be low (Clarke \& Wardman, 1985). It is time for clinicians to accept the possibility of nonassociative pathways to fear.

Finally, some comment about the future direction of research on the associative learning model should be made. The present authors agree with Davey (1992), who argues that a principle obstacle in determining the scope of the conditioning model across phobias is the lack of adequate empirical evidence. The extent to which various associative phenomena, such as latent inhibition, sensory preconditioning, and UCS revaluation can be identified in the development of human phobias needs to be determined. To date, too few studies have considered these phenomena. 


\section{REFERENCES}

American Psychiatric Association. (1980). Diagnostic and statistical manual of mental disorders (3rd ed). Washington, DC: Author.

Baker, B. L., Cohen, D. C., \& Saunders, J. T. (1973). Self-directed desensitization for acrophobia. Behaviour Research and Therapy, 11, 79-89.

Bancroft, J. H. J., \& Marks, I. M. (1968). Electric aversion therapy of sexual deviations. Proceedings of the Royal Society of Medicine, 61, 796-798.

Bandura, A. Blanchard, E. B., \&c Ritter, B. (1969). Relative efficacy of desensitization and modelling approaches for inducing behavioral, affective and attitudinal changes. Joumal of Personality and Social Psychology, 13, 173-199.

Bandura, A., \& Rosenthal, T. L. (1966). Viacrious classical conditioning as a function of arousal level. Journal of Personality and Social Psychology, 3, 54-62.

Bersh, P. J. (1980). Eysenck's theory of incubation: A critical analysis. Behaviour Research and Therapy, 18, 13-17.

Bertenthal, B. I., \& Campos, J. J. (1984). A reexamination of fear and its determinants on the visual cliff. Psychophysiology, 21, 413-417.

Bertenthal, B. I., Campos, J. J., \& Barrett, K. C. (1984). Self-produced locomotion: An organizer of emotional, cognitive, and social development in infancy. In R. Emde \& R. Harmon (Eds.), Continuities and discontinuities in development (pp. 175-210). New York: Plenum Press.

Black, A. H., Carlson, 'N. J., \& Solomon, R. I. (1962). Exploratory studies of the conditioning of autonomic responses in curarized dogs. Psychological Monographs, Whole Number 548, 1-31.

Bolles, R. C., \& Faneslow, M. S. (1980). A perceptual-defensive-recuperative model of fear and pain. Behavioural and Brain Sciences, 3, 291-323.

Bowlby, J. (1975). Attachment and loss (Vol. 2). London: Penguin.

Bregman, E. (1934). An attempt to modify the emotional attitude of infants by the conditioned response technique. Joumal of Genetic Psychology, 45, 169-198.

Bridger, W., \& Mandel, C. (1964). A comparison of GSR fear responses produced by threat and electric shock. Journal of Psychiatric Research, 2, 31-40.

Brown, I. (1974). Effects of perceived similarity on vicarious emotional conditioning. Behaviour Research and Therapy, 12, 165-173.

Campbell, D., Sanderson, R. E., \& Laverty, S. C. (1964). Characteristics of a conditioned response in human subjects during extinction trials following a simple traumatic conditioning trial. Journal of Abmormal and Sacial Psychology, 68, 627-639.

Campos, J. J., Hiatt, S., Ramsay, D., Henderson, C., \& Svejda, M. (1978). The emergence of fear on the visual cliff. In M. Lewis \& L. A. Rosenblum (Eds.), The development of affect (pp. 149-181). New York: Plenum.

Carr, A. T. (1979). The psychopathology of fear. In W. Sluckin (Ed.), Fear in animals and man (pp. 199-235). New York: Van Nostrand Reinhold.

Clarke, J. C., \& Jackson, J. A. (1983). Hypnosis and behavior therapy: The treatment of anxiety and phobias. New York: Springer.

Clarke, J. C., \& Wardman, W. (1985). Agoraphobia: A clinical and personal account. Sydney: Pergamon.

Cohen, D. C. (1977). Comparisons of self-report and overt-behavioral procedures for assessing acrophobia. Behavior Therapy, 18, 17-23.

Cook, E. (1983). Human classical conditioning and the preparedness hypothesis. Unpublished doctoral dissertation, University of Wisconsin, Madison.

Cook, S. W., \& Harris, R. E. (1937). The verbal conditioning of the galvanic skin reflex. Journal of Experimental Psychology, 21, 202-210.

Costello, C. G. (1970). Dissimilarities between conditioned avoidance responses and phobias. Psychological Review, 99, 250-254.

Craig, K, \& Lowery, J. (1969). Heartrate components of conditioned viacrious response. Journal of Personality and Social Psychology, 11, 381-387.

Darwin, C. (1877). A biographical sketch of an infant. Mind, 2, 285-294.

Davey, G. C. L. (1989). Dental phobias and anxieties: Evidence for conditioning processes in the acquisition and modulation of a learned fear. Behaviour Research and Therapy, 27, 51-58.

Davey, G. C. L. (1992). Classical conditioning and the acquisition of human fears and phobias: A review and synthesis of the literature. Advances in Behaviour Research and Therapy, 14, 29-66.

Dawson, M. E., Schell, A. M., \& Tweddle-Banis, H. (1986). Greater resistance to extinction of electrodermal responses conditioned to potentially phobic CSs: A noncognitive process? Psychophysiology, 23, 522-561.

Delprato, D. J. (1980). Hereditary determinants of fears and phobias: A critical review. Behavior Therapy, 11, 79-103. 
Delprato, D. J., \& McGlynn, F. D. (1984). Behavioral theories of anxiety disorders. In S. M. Turner (Ed.), Behavioral theories and treatment of anxiety. New York: Plenum.

Dennis, W. (1940). Does culture appreciably affect patterns of infant behavior? Journal of Social Psychology, 12, 305-317.

De Silva, P., Rachman, S., \& Seligman, M. E. P. (1977). Prepared phobias and obsessions: Therapeutic outcome. Behaviour Research and Therapy, 15, 65-77.

Dimond, S. (1966). Imprinting and fear - A system governed by visual experience during the development of the embryo. Bulletin of the British Psychological Society, 19, 63-4.

Di Nardo, P. A., Guzy, L. T., Jenkins, J. A., Bak, R. M., Tomasi, S. F., \&e Copland, M. (1988). Etiology and maintenance of dog fears. Behaviour Research and Therapy, 26, 241-244.

Emlin, J. T. (1963). Determinants of cliff edge and escape responses in herring gull chicks. Behaviour, 22, 1-15.

Emlen, S. (1970). The influence of magnetic information on the orientation of the indigo bunting (Passerina Cyanea). Animal Behavior, 18, 215-224.

English, H. B. (1929). Three cases of the conditioned fear response. Joumal of Abnomal and Social Psychology, 24, 221-225.

Eysenck, H. J. (1976). The learning theory model of neurosis - A new approach. Behaviour Research and Therapy, 14, 251-267.

Eysenck, H. J. (1979). The conditioning model of neurosis. Behavioural and Brain Sciences, 2, 155-199.

Fazio, A. F. (1972). Implosive therapy with semiclinical phobias. Journal of Abnormal Psychology, 80, $183-188$.

Freedman, D. (1965). Hereditary control of early social behavior. In B. M. Foss (Ed.), Determinants of infant behavior III (pp. 149-155). London: Methuen.

Freud, S. (1909). An analysis of a phobia in a five-year-old-boy. In Case Histories 1 - Dora and Little Hans. London: Penguin, 1977.

Gibson, E. J., \& Walk, R. D. (1960). The "visual cliff." Scientific American, 202(4), 64-71.

Gray, J. A. (1971). The psychology of fear and stress. London: Weidenfeld \& Nicholson.

Gray, J. A. (1979). Is there any need for conditioning in Eysenck's conditioning model of neurosis? Behavioural and Brain Sciences, 2, 169-171.

Grings, W. W. (1973). Cognitive factors in electrodermal conditioning. Psychological Bulletin, 79, 200-210.

Grinker, R., \& Spiegel (1945). Men under stress. London: Churchill.

Hagman, E. (1932). A study of fears of children of preschool age. Journal of Experimental Education, 1 , 110-130.

Hallam, R. S., \& Rachman, S. (1976). Current status of aversion therapy. In M. Hersen, R. M. Eisler, \& P. M. Miller (Eds.), Progress in behaviour modification (Vol. 2). New York: Academic Press.

Hallam, R. S., Rachman, S., \& Falkowski, W. (1972). Subjective, attitudinal and physiological effects of electrical aversion therapy. Behaviour Research and Therapy, 10, 1-14.

Hebb, D. O. (1946). On the nature of fear. Psychalogical Review, 53, 259-276.

Hetherington, E. M., \& Parke, R. D. (1982). Child psychology: A contemporary viewpoint. Tokyo: McGraw-Hill.

Hodes, R. L. (1981). A psychophysiological investigation of the classical conditioning model of fears and phobias. Unpublished doctoral dissertation, University of Wisconsin, Madison.

Hugdahl, K. \& Ohman, A. (1977). Effects of instruction on acquisition and extinction of electrodermal responses to fear-relevant stimuli. Journal of Experimental Psychology: Human Learning and Memory, 3, 608-618.

Hugdahl, K, \& Ohman, A. (1980). Skin conductance conditioning to potentially phobic stimuli as a function of interstimulus interval and delay versus trace paridigm. Psychophysiology, 17, 348-355.

Hygge, S. (1976). Information about the models unconditioned stimulus and response in vicarious classical conditioning. Journal of Personality and Social Psychology, 33, 764-771.

John, E. (1941). A study of the effects of evacuation and air-raids on preschool children. British Jourmal of Educational Psychology, 11, 173-179.

Jones, M. K., \& Menzies, R. G. (1994) The etiology of fear of spiders. Unpublished manuscript.

Kagan, J., Kearsley, R. B., \& Zelazo, P. R. (1978). Infancy: Its place in human development. Cambridge, MA: Harvard University Press.

Kimble, G. (1961). Hilgard and Marquis, “conditioning and learning.” New York: Appleton-Century-Crofts.

Kimmel, H. D. (1979). Eysenck's model of neurotigenesis. Behavioural and Brain Sciences, 2, 171-172.

Kleinknecht, R. D. (1982). The origins and remission of fear in a group of tarantula enthusiasts. Behaviour Research and Therapy, 20,437-443.

Kraemer, G. W. (1985). Effects of differences in early social experience on primate neurobiological-behavioral development. In M. Reite \& T. Field (Eds.), The psychobiology of attachment (pp. 135-161). New York: Academic.

Kravetz, D. (1974). Heart rate as a minimal cue for the occurrence of vicarious classical conditioning. Journal of Personality and Social Psychology, 29, 125-131. 
Lazarus, A. A. (1971). Behavior therapy and beyond. New York: McGraw-Hill.

Levis, D. J. (1970). Between-trial transporting of animals: A methodological consideration. Behaviour Research Methods and Instrumentation, 2, 157-160.

Levis, D. J. (1971). One-trial-a-day avoidance learning. Behavioural Reseanch Methods and Instrumentation, 3, 65-67.

Levis, D. J. (1979). A reconsideration of Eysenck's conditioning model of neurosis. Behavioral and Brain Sciences, 2, 172-174.

Levis, D. J., Bouska, S., Eron, J., \& McIIhon, M. (1970). Serial CS presentation and one-way avoidance conditioning: A delayed responding. Psychonomic Science, 20, 147-149.

Liddell, A, \& Lyons, M. (1978). Thunderstorm phobias. Behaviour Research and Therapy, 16, 306-308.

Mackintosh, N. J. (1974). The psychology of animal learning. London: Academic Press.

Maltzman, H., \& Boyd, G. (1984). Stimulus significance and bilateral SCRs to potentially phobic pictures. Journal of Abnormal Psychology, 93, 41-46.

Marks, I. M. (1969). Fears and phobias. London: Heinemann.

Marks, I. M. (1987). Fears, phobias and rituals: Panic, anxiety and their disorders. New York: Oxford University Press.

Marks, I. M., \& Mathews, A. M. (1979). Brief standard self-rating for phobic patients. Behaviour Research and Therapy, 17, 263-267.

Mattick, R. P. (1987). Nature and treatment of social phobia. Unpublished doctoral dissertation, University of New South Wales, Sydney.

McAllister, W. R., \& McAllister, D. E. (1979). Are the concepts of enhancement and preparedness necessary. Behavioural and Brain Sciences, 2, 177-178.

McKinney, W. T. (1985). Separation and depression: Biological markers. In M. Reite \& T. Field (Eds.), The psychobiology of attachment (pp. 201-222). New York: Wiley.

McNally, R. J. (1987). Preparedness and phobias: A review. Psychological Bulletin, 101, 283-303.

McNally, R. J., \& Foa, E. B. (1986). Preparedness and resistance to extinction to fear-relevant stimuli: A failure to replicate. Behaviour Research and Therapy, 24, 529-535.

McNally, R. J., \& Reiss, S. (1984). The preparedness theory of phobias: The effects of initial fear level on safety-signal conditioning to fear-relevant stimuli. Psychophysiology, 21, 647-652.

McNally, R. J., \& Steketee, G. S. (1985). The etiology and maintenance of severe animal phobias. Behaviour Research and Therapy, 23, 431-435.

Menzies, R. G., \& Clarke, J. C. (1993a). The etiology of childhood water phobia. Behaviour Research and Therapy, 31, 499-501.

Menzies, R. G., \& Clarke, J. C. (1993b) The etiology of fear of heights and its relationship to severity and individual response patterns. Behaviour Research and Therapy, 31, 355-365.

Menzies, R. G., \& Clarke, J. C. (1994) The etiology of acrophobia and its relationship to severity and individual response patterns. Unpublished manuscript.

Merckelbach, H., De Ruiter, C., Van De Hout, M. A., \& Hoekstra, R. (1989). Conditioning experiences and phobias. Behaviour Reseanch and Therapy, 27, 657-662.

Merckelbach, H., Van Den Hout, M. A., Hoekstra, R., \& Van Oppen, P. (1988). Are prepared fears less severe, but more resistant to extinction? Behaviour Research and Therapy, 26, 527-530.

Michelson, L. (1986). Treatment consonance and response profiles in agoraphobia: The role of individual differences in cognitive, behavioural and physiological treatments. Behaviour Research and Therapy, 24, 263-275.

Mineka, S. (1982). Depression and helplessness in primates. In H. E. Fitzgerald, J. A. Mullins, \& P. Gaze (Eds.), Child nurturance (Vol. 3, pp. 197-242). New York: Plenum.

Moro, E. (1918). Das erste trimenon. Munch. Med. Wschr, 65, 1147-1150.

Mowrer, O. H. (1939). A stimulus-response analysis of anxiety and its role as a reinforcing agent. Psychological Review, 46, 553-565.

Munjack, D. J. (1984). The onset of driving phobias. Journal of Behavior Therapy and Experimental Psychiatry, $15,305-308$.

Murray, E. J., \& Foote, F. (1979). The origins of fear of snakes. Behaviour Research and Therapy, 17, 489-493.

Nicholaichuk, T. P., Quesnel, L. J., \& Tait, R. W. (1982). Eysenck's theory of incubation: An empirical test. Behaviour Research and Therapy, 20, 329-338.

Ohman, A. (1979). Fear relevance, autonomic conditioning, and phobias: A laboratory model. In P.-O. Sjoden, S. Bates, \& W. S. Dockens, III (Eds.), Trends in behavior therapy. New York: Academic.

Ohman, A., \& Dimberg, U. (1978). Facial expressions as conditioned stimuli for electrodermal responses: A case of "preparedness"? Journal of Personality and Social Psychology, 36, 1251-1258.

Ohman, A., Dimberg, U., \& Ost, L.-G. (1985). Animal and social phobia: Biological constraints on learned fear responses. In S. Reiss \& R. R. Bootzin (Eds.), Theoretical issues in behaviour therapy (pp. 123-175). New York: Academic Press. 
Ohman, A., Eriksson, A., \& Olofsson, C. (1975). One-trial learning and superior resistance to extinction of autonomic responses conditioned to potentially phobic stimuli. Journal of Comparitive and Physiological Psychology, 88, 619-627.

Ohman, A., Erixson, G., \& Lofberg, I. (1975). Phobias and preparedness: Phobic versus neutral pictures as conditioned stimuli for human autonomic responses. Journal of Abnomal Psychology, 84, 41-45.

Ohman, A., Fredrikson, M., Hugdahl, K, \& Rimmo, P. (1976). The premise of equipotentiality in human classical conditioning: Conditioned electrodermal responses to potentially phobic stimuli. Journal of Experimental Psychology: General, 105, 313-337.

Ohman, A., \& Hugdahl, K. (1979). Instructional control of autonomic respondents: Fear relevance as a critical factor. In N. Birbaumer \& H. D. Kimmel (Eds.), Biofeedback and self-regulation (pp. 149-165). New York: Wiley.

Ost, L.-G. (1985). Ways of acquiring phobias and outcome of behavioural treatments. Behaviour Research and Therapy, 23, 683-689.

Ost, L.-G. (1991). Acquisition of blood and injection phobia and anxiety response patterns in clinical patients. Behaviour Research and Therapy, 29, 323-332.

Ost, L.-G., \& Hugdahl, K (1981). Acquisition of phobias and anxiety response patterns in clinical patients. Behaviour Research and Therapy, 19, 439-447.

Ost, L.-G., \& Hugdahl, K. (1983). Acquisition of agoraphobia, mode of onset and anxiety response patterns. Behaviour Research and Therapy, 21, 623-632.

Ost, L.-G., \& Hugdahl, K. (1985). Acquisition of blood and dental phobia and anxiety response patterns in clinical patients. Behaviour Research and Therapy, 23, 27-34.

Pavlov, I. P. (1927). Conditioned reflexes. London: Oxford University Press.

Pendleton, M. G., \& Higgins, R. L. (1983). A comparison of negative practice and systematic desensitization in the treatment of acrophobia. Journal of Behavior Therapy and Experimental Psychiatry, 14, 317-323.

Plomin, R., \& Rowe, D. C. (1979). Genetic and environmental etiology of social behavior in infancy. Developmental Psychology, 15, 62-72.

Rachman, S. (1976). The passing of the two-stage theory of fear and avoidance: Fresh possibilities. Behaviour Research and Therapy, 14, 125-131.

Rachman, S. (1977). The conditioning theory of fear acquisition: A critical examination. Behaviour Research and Therapy, 15, 375-387.

Rachman, S. (1983). Irrational thinking, with special reference to cognitive therapy. Advanced Behaviour Research and Therapy, 5, 63-88

Rachman, S. (1984). Agoraphobia: A safety-signal perspective. Behaviour Restisrch and Therapy, 22, 59-70.

Reiss, S. (1980). Pavlovian conditioning and human fear: An expectancy model. Behavior Therapy, 11, 380-396.

Reiss, S. (1991). Expectancy model of fear, anxiety and panic. Clinical Psychology Review, 11, 141-153.

Rescorla, R. A. (1972). Informational variables in Pavlovian conditioning. In G. H. Bower (Ed.), The psychology of learning and motivation (Vol 6). New York: Academic Press

Richards, J., \& Rader, N. (1983). Affective, behavioral, and avoidance responses on the visual cliff: Effects of crawling onset age, crawling experience, and testing age. Psychophysiology, 20, 633-642.

Rimm, D. C., Janda, L. H., Lancaster, D. N., Nahl, M., \& Dittmar, K. (1977). An exploratory investigation of the origin and maintenance of phobias. Behaviour Research and Therapy, 15, 231-238.

Robeck, M. C. (1978). Infants and children: Their development and learning. New York: McGraw-Hill.

Routtenberg, G. A., \& Glickman, S. E. (1964). Visual cliff behavior in undomesticated rodents, land and aquatic turtles and cats. Journal of Comparitive and Physiological Psychology, 58, 143-146.

Sackett, G. P. (1966). Monkeys reared in isolation with pictures as visual input. Science, 154, 1468-1472.

Salzen, E.A. (1979). The ontogeny of fear in animals. In W. Sluckin (Ed.), Fear in animals and man (pp. 125-128). London: Van Nostrand.

Scarr, S., \& Salapatek, P. (1970). Patterns of fear development during infancy. Merrill-Palmer Quarterly, 16, 53-90.

Schneirla, T. C. (1972). Interrelationships of the "innate" and the "acquired" in instinctive behavior. In L. R. Aronson (Ed.), Selected writings of T. C. Schneirla. San Francisco: W. H. Freeman.

Seligman, M. E. P. (1970). On the generality of the laws of learning. Psychological Review, 77, 406-418.

Seligman, M. E. P. (1971). Phobias and preparedness. Behavior Therapy, 2, 307-320.

Scarr, S., \& Salapatek, P. (1970). Patterns of fear development during infancy. Merrill-Palmer Quarterly, 16, 53-90.

Smith, P. K. (1979). The ontogeny of fear in children. In W. Slukin (Ed.), Fear in animals and man (pp. 164-168). London: Van Nostrand.

Solomon, R. L., \& Wynne, L. C. (1954). Traumatic avoidance learning: The principles of anxiety conservation and partial irreversibility. Psychological Review, 61, 358-385. 
Stampfl, T. G. (1991). Analysis of aversive events in human psychopathology: Fear and avoidance. In M. R. Denny (Ed.), Fear, avoidance, and phobias: A fundamental analysis. Hillsdale, NJ: Lawrence Erlbaum Associates.

Sturgis, E. L., \& Scott, R. (1984). Simple Phobia. In S. M. Turner (Ed.), Behavioral theories and treatment of anxiety (pp. 91-141). New York: Plenum Press.

Thorndike, E. L. (1898). Animal intelligence. New York: Macmillan.

Thorndike, E. L. (1935). The psychology of wants, interests, and attitudes. New York: Appleton-Century-Crofts. Thyer, B., Hilme, J., \& Curtis, G. (1985). Blood-injury-illness phobia: A review. Journal of Clinical Psychology, 41, 451-459.

Tinbergen, N. (1951). The study of instinct. Oxford: University Press.

Valentine, C. W. (1930). The innate bases of fear. Journal of Genetic Psychology, 37, 394-419.

Wagner, A. R., Siegel, L. S., \& Fern, G. G. (1967). Extinction of conditioned fear as a function of percentage of reinforcement. Jourmal of Comparitive and Physiological Psychology, 63, 160-164.

Walk, R., \& Gibson, E. J. (1961). A comparitive and analytic study of visual depth perception. Psychological Monographs, 75(15, Whole No. 519), 1-44.

Watson, J. B. (1919). Psychology from the standpoint of a behaviorist. Philadelphia: Lippincott.

Watson, J. B. (1924). Behaviorism. New York: Norton.

Watson, J. B., \& Morgan, J. J. B. (1917). Emotional reactions and psychological experimentation. American Jourmal of Psychology, 28, 163-174.

Watson, J. B., \& Rayner, R. (1920). Conditioned emotional reactions. Joumal of Experimental Psychology, 3(1), 1-14.

Williams, S. L., \& Watson, N. (1985). Perceived danger and perceived self-efficacy as cognitive determinants of acrophobic behavior. Behavior Therapy, 16, 136-146.

Willis, L. M. (1983). The aetiology, assessment, and treatment of children's phobic fear of water. Unpublished honours thesis, University of New South Wales, Sydney.

Windheuser, H. J. (1977). Anxious mothers as models for coping with anxiety. Behavioural Analysis and Modification, 1, 39-58.

Wolpe, J. (1981). The dichotomy between classical conditioned and cognitively learned anxiety. Journal of Behavior Therapy and Experimental Psychiatry, 12, 35-42.

Wolpe, J., Lande, S. D., McNally, R. J., \& Schotte, D. (1985). Differentiation between classically conditioned and cognitively based neurotic fears: Two pilot studies. Journal of Behavior Therapy and Experimental Psychiatry, 16, 287-293.

Wolpe, J., \& Lang, P. J. (1964). A fear schedule for use in behavior therapy. Behaviour Research and Therapy, 2, 27-30.

Wolpe,J., \& Rachman, S. (1960). Psychoanalytic "evidence": A critique based on Freud's case of Little Hans. Jourmal of Nervous and Mental Disease, 131, 135-147.

Zafiropoulou, M., \& McPherson, F. M. (1986). Preparedness and the severity and outcome of clinical phobias. Behaviour Research and Therapy, 24, 221-222.

This article is being published without benefit of the authors' review of the corrected proof as this was not available at press time. 